\section{Military Technical College Kobry El-Kobbah, Cairo, Egypt}

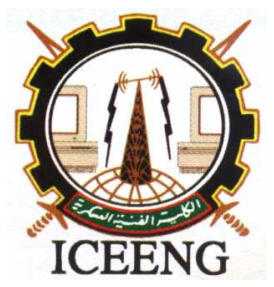

\title{
AGC with Fuzzy controller parameters are tuned by GA
}

$$
\text { By }
$$

\author{
Hakan Saracoglu *
}

\author{
Aysen Demiroren *
}

\section{Abstract:}

This paper presents a method based on fuzzy logic controllers and genetic algorithm technique for automatic generation control (AGC) of power systems. In this study, ordinary fuzzy PI controller and fuzzy PI controller that its parameters are tuned by using genetic algorithm technique also used as load-frequency controllers with classical integral controller. The proposed control has been designed to control systems include three areas having two steam turbines and one hydro turbine and include two areas having two steam turbines tied together through power lines. The load perturbation to first area of power systems that its simulation models is designed and implemented by using computer program is applied. As result of this, changing frequency and tie-line exchange power values is retrieve back to their desired values by using three different kinds of controllers. From the obtained results, it is shown that the performance of fuzzy PI controller that its gain parameters tuned by using GA outperforms than other controller configurations.

\section{Keywords:}

Automatic generation control, fuzzy control, area control error, genetic algorithm

* Department of Electrical Engineering, Electric and Electronic Faculty, İstanbul Technical University 34469, Maslak, İstanbul 80626, Turkey 


\section{Introduction:}

In nowadays that power systems's sizes are increasing and being more complexity, automatic generation control (AGC) problem of structures consist of parallel operation of several interconnected systems is one of important subjects in power system studies. When unpredictable area load variations and abnormal conditions such as outages of generation happened in power systems with two or more areas, this lead to mismatches in frequency and scheduled power interchanges between areas, in interconnected systems with primary speed control action, can be stopped mismatches in frequency and scheduled power interchanges between areas but frequency and power interchange values can not be returned back to in predetermineted limits, these mismatches have to be corrected via supplementary control that's why the interconnected power system need to a supplementary controller. AGC based on the idea that reference set point of generators in control areas are controlled by using supplementary controller. Automatic generation control is defined as regulation of power output of generators within a prescribed area, in response to change in system frequency, tie-line loading or the relation of these to each other; so as to maintain scheduled system frequency and/or established interchange with other areas within predetermined limits [1]. The objective of AGC is to minimize the transient deviations and to provide zero steady state errors of these variables. In literature, for AGC, some control strategies based on classical control theory have been proposed [2,3], but because of operation point continuously changes depending on demand of consumers, the selected fixed controller can unsuitable other operating points that is why expected performance can not be achieved by the fixed controller for many times therefore in literature researchers have proposed different control strategies with variable structures $[4,5,6,7]$. One of the most successful control methods is controllers based on fuzzy logic. Fuzzy logic controllers have some advantages as like it provides an efficient way of coping with imperfect information, especially imprecision in available knowledge, one of its main advantages is that controller parameters can be changed very quickly by the system dynamics because no parameter estimation is required in designing controller for nonlinear systems. Moreover, this control method does not need an accurate model of the dynamics of system under control.

In this study, AGC of two power systems that one of them consist of three areas having two steam turbines and one hydro turbine, other system consist of two areas having two steam turbines is considered. In order to control to this power systems, three controllers type, conversional PI controller, fuzzy PI controller and fuzzy PI controller that its gain parameters are tuned by using GA, is used. The simulation models of power systems are implemented by using MATLAB Simulink Program and MATLAB Fuzzy Logic Toolbox and Genetic Algorithm Toolbox. To damp out the oscillations due to instantaneous load perturbations in first area of power systems in simulation model, 
using three controllers type uses AGC of power systems.

One of characteristic specifications of this study is that the governors at all areas in power system have deadband, which are important for speed control under small disturbances. The deadband affects the stability of the power system. It is known that governor deadband has destabilization effect on the transient response. Moreover, reheater effects are very important for stability of the systems having steam turbines having steam turbine therefore, the effects of reheater of each thermal area in the power system considered in this study and is modelled in simulation [8].

\section{Modelling for Automatic Generation Control of Power Systems:}

An interconnected power system is considered as being divided into control areas, which are connected by tie lines. In each control area, all generators are assumed to form a coherent group. Some of the areas in the power system are considered having load perturbations having same magnitudes Hence, it is required to control the deviations of frequency and tie-line power of each control area. The power systems investigated in the study, consisting of three areas and two areas. The power system with two areas is assumed to contain two reheat turbine type thermal units. The power system with three areas is assumed to contain two reheat turbine type thermal units and a hydro unit. The detailed block diagram of the interconnected power system with three areas is given in Fig. 1.

Each area supplies electric power to its own customer and tie lines allow electric power to flow between areas. Therefore, each area affects others; it is mean that when unpredictable load variations occured in any area, this situation affect frequency and tie line exchanges values in other areas. The control system of each area needs information about transient situation in all areas to bring the frequency and tie-line exchange to their steady state value. Hence, control system is able to bring them to their steady state value.

In AGC, controller that controls power system accepts error singal as input signal. This error signal is called as area control error (ACE)

$\mathrm{ACE}=\mathrm{b}_{\mathrm{i}} \Delta \mathrm{f}_{\mathrm{i}}+\Delta \mathrm{P}_{\mathrm{i}}$

Here, bi is frequency bias factor and optimal value of bi is chosen as 0.425 in literature [9].

Controller brings system frequency and tie-line interchange power values back to their predetermineted values by using ACE.

The function approach described is used to incorporate governor deadband nonlinearity in literature [10]. In has been found that the backlash nonlinearity tends to produce a continuous sinusoidal oscillation with a natural period of about 2 sn. An approximate Fourier series solution has been developed as follows: 


$$
\mathrm{F}(\mathrm{x}, \mathrm{dx} / \mathrm{dt})=0.8 \mathrm{x}-\frac{0.2}{\pi} \mathrm{dx} / \mathrm{dt}
$$

where the above Fourier coefficients stand for a backlash of \%0.05 [10].

\section{PI Controller:}

Conventionel PI controller is proposed first controller type for the AGC of power system in this study. The reason behind the extensive use of PI controllers is its effectiveness in the control of steady-state error of a control system. This controller type brings down the steady-state error to zero. Integral controller gain (Ki) decrease the rise time, increases both the overshoot and the settling time, and eliminates the steady-state error. In this paper, ACE is controlled as steady-state error that needs controlling. PI controller, which is used as load-frequency controller, produces a control signal (u) in order to bring down area control error to zero. This control signal (u) provide to maintain frequency and interchange power in predetermineted values The block diagram of PI controller are shown in Fig. 2. Control signal (u) is defined with below formulation:

$$
u_{i}=-K_{i} \int_{0}^{j}\left(A C E_{i}\right) d t=-K_{i}^{j} j_{0}^{j}\left(\Delta P_{w i . i}+b_{i} \Delta f_{i}\right) d t
$$

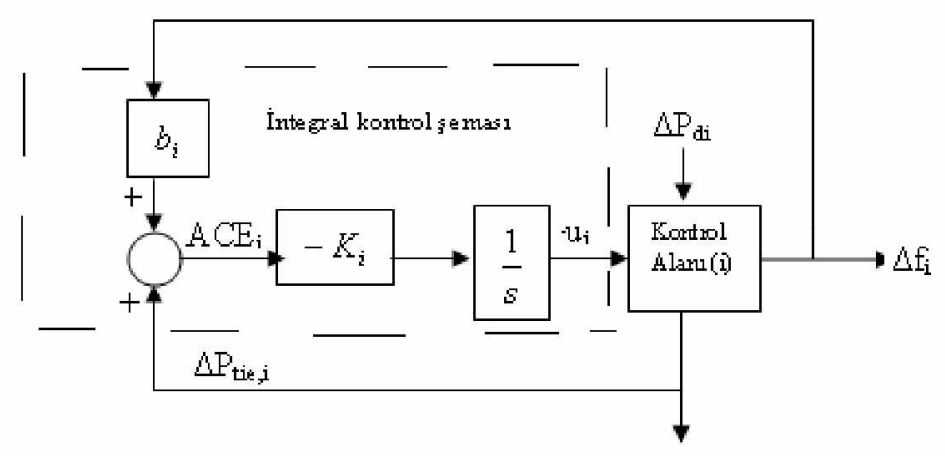

Figure (2): Block diagram of conventional PI controller

\section{Fuzzy Logic Controllers:}

One of the main aims of this study is AGC of power systems with two and three areas by using fuzzy logic controller. The reason of choosing fuzzy logic controllers is that controller parameters can be changed very quickly by the system dynamics because no parameter estimation is required in designing controller for nonlinear systems. Therefore a FLC, which represents a model-free type of nonlinear control algorithms, could be a reasonable solution for investigated problem type.

In this paper, the inputs of proposed fuzzy controllers are ACE and change rate in 
ACE ( $\triangle \mathrm{ACE})$, which is indeed error (e) and the derivation of the error (de/dt) of the system. The inputs of controller is shown in Fig. 3.

Proposed controller is Sugeno type fuzzy PI controller with two input and one output. In this controller, error and derivation of error signals which have numeric value are multipled by scaling factors then numeric values is transformed into fuzzy sets. This fuzzy sets represented by membership functions is processing by inference engine according to rules in to rule base. The result of the inference process is an output represented by a fuzzy set, but the output of fuzzy system should be a numeric value, the transformation of a fuzzy set into a numeric value is called defuzzification. This numeric value is multipled by output scaling factor and be produced output control signal (u). Input and output scaling factors tune the fuzzy controller to obtain the desired dynamic response of power system.

In proposed fuzzy controller, shape of the membership functions of ACE and $\triangle \mathrm{ACE}$ is gaussian as shown in Fig. 4. There is $3 \times 3=9$ rules in rule base of proposed fuzzy controller. In literatute, $5 \times 5=25$ or $7 \times 7=49$ rules and triangle shaped membership functions are mostly used in fuzzy controller for AGC. The reason of using proposed membership function shape and 9 rules is that the performance of controller designed according to proposed parameter is very close to response found for controller with 49 rules and triangle shaped membership function, and also designing controller for 9 rules is very easy. NB,NS,Z,PS,PB in lookup table of fuzzy rules represent negative big, negative small, zero, positive small, positive big, respectively.

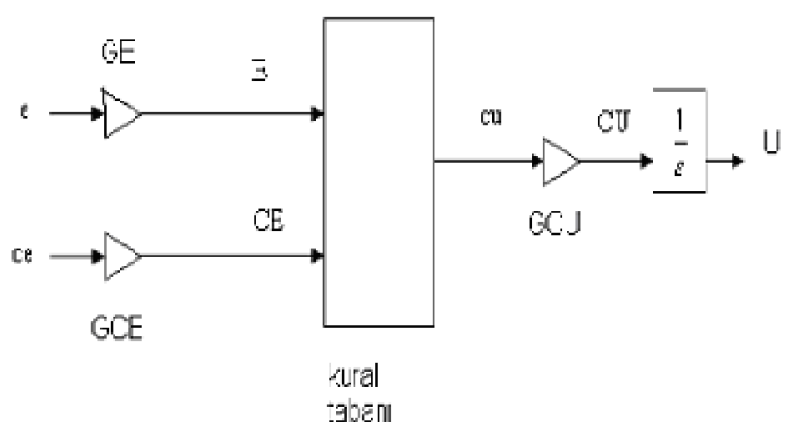

Figure (3): Fuzzy PI type controller 




Figure (4): Membership functions of $A C E$ and $\triangle A C E$

\section{Genetic Algorithm:}

In this study, the optimum values of the parameters KIi and bi which minimize an array of different performance indices, are easily and accurately computed using a genetic algorithm. In a typical run of the GA, an initial population is randomly generated. This initial population is referred to as the 0th generation. Each individual in the initial population has an associated performance index value. Using the performance index information, the GA then produced a new population. The application of a genetic algorithm involves repetitively performing two steps.

1.The calculation of the performance index for each of the individuals in the current population. To do this, the system must be simulated to obtain the value of the performance index.

2. The genetic algorithm then produces the next generation of individuals using the reproduction, crossover and mutation operators.

These two steps are repeated from generation to generation until the population has converged, producing the optimum parameters [11]. In this paper, the integral of squared time-multiplelied square of error) is considered as performance index.

$\int_{0}^{2} t^{2}\left(\Delta P_{12}^{2}+\Delta P_{23}^{2}+\Delta P_{31}^{2}+\alpha \Delta f_{1}^{2}+\beta \Delta f_{2}^{2}+\lambda \Delta f_{3}^{2}\right) d t$

In this study, GA utilized to tune gain parameters of fuzzy PI controller. To calculate the performance index, a digital simulation of the system was designed and performed for each of the individuals of the current population. The values of the performance indices thus obtained, were fed to genetic algorithm in order to produce the next generation of individuals. The procedure is repeated until the population has converged to some minimum value of the performance index producing near optimal parameters set. The following genetic algorithm parameters were used in the present research.

Population size: 50

Maximum no. Of generations: 245

Crossover probability: 0.8

Mutation probability: 0.1 


\section{Results and Analysis:}

In this study, the AGC of interconnected power systems with two and three areas by using three different type controller, conversional PI controller, fuzzy PI controller and fuzzy PI controller that its gain parameters tuned by using GA, is considered. Through simulations, the performance of proposed controllers is shown and compared.

The simulation models of proposed power systems are implemented by using MATLAB Simulink Program and MATLAB Fuzzy Logic Toolbox and Genetic Algorithm Toolbox. The load perturbation having amplitude of 0.01 p.u. MW to the fist areas of power systems is applied and the frequency oscillations and tie-line power flows are investigated. Because of governor deadband negative effect on settling time and on the amplitude of oscillations and reheater effects are very important for stability of the systems having steam turbines, in the simulation, detailed model incorporates governor deadband nonlinearity effects and steam reheat process using the describing function approach. The system responses with three controllers are shown in Fig. 5. Which response belongs to which controller is shown on the figure.

The aim of the study is to investigate the effects of fuzzy PI controller and fuzzy PI controller that its gain parameters tuned by using GA on improving dynamic performance of the power system. The results obtained show that the performance of fuzzy PI controller that its gain parameters tuned by using GA is better than ordinary fuzzy PI controller and conventional PI controller as the main objective of the study. It is observed that the settling time of this control strategy is much shorter than other controller type and with the proposed controller less overshoot and undershoot is observed.

\section{Conclusions:}

This study is an application of three control strategies to AGC in power systems with two and three areas. Computer programs implement simulation of power systems. In power systems with two and three areas, which the load perturbation to first area of power systems is applied, tie-line exchange power deviations and steady state performance of frequency for each areas is investigated. This exchange power deviations and steady state performance of frequency that is not desirable cause an ACE in the power system. Companies producing electric power have to bring down the area control area to zero in order to ensure the quality of power supply. Proposed controllers provide to maintain system frequency and exchange power values within predetermined limits and in this way, ACE is brought down to zero.

From the obtained results, it is shown that the performance of fuzzy PI controller than its gain parameters tuned by using GA outperforms than other controller configurations 
at AGC in power system.

\section{References:}

[1] Hiyama, T. and Koya, S. and Yoshimuta, Y., 2000. Fuzzy Logic Based MultiFunctional Load Frequency Control, IEEE 2000, 921-926.

[2] P. Agathoklis and M.H. Hamza, Comparison of three algorithms for load frequency control. Electr. Power Syst. Res., 7 (1984) 165-172

[3] A.Bose and I. Atiyyah. Regulation error in load frequency control, IEEE Trans. Power Apar. Syst., PAS-99 (2) (1980).

[4] T. Kennedy, S.M. Hoyt and C.F. Abell, Variable, non-linear tie-line frequency bias for interconnected systems control, IEEE Trans. Power Syst., 3 (3) (1988).

[5] Z.M. Ai-Hamouz and Y.L. Abdel-Magid, Variable structure load frequency controllers for multiarea power systems. Int. J. Electr. Power Energy Syst., 15 (5) (1993).

[6] A. Kumar, O. P. Malik and G.S. Hope, Variable-structure-system control applied to AGC of an interconnected power system, IEE Proc., 132 Pt. C (1) (1985).

[7] A. Rubaai and V. Udo, An adaptive control scheme for load-frequency control of multiarea power systems. Part I ve II. Electr. Power Syst. Res., 24 (1982).

[8] A. Demiroren and E. Yesil, Automatic generation control control with fuzzy logic controllers in the power system including SMES units, Electr. Power and Energy Syst. 26 (2004) 291-305.

[9] Demirören, A. and Zeynelgil, L., 2004. Elektrik

Enerji Sistemlerinin Kararlılığı Kontrolu ve Çalışması

Birsen Yayınevi, İstanbul

[10] C.S. Chang and Weihui Fu, Area load frequency control using fuzzy gain Schedule of PI controllers, Electr. Power Syst. Research 42 (1997) 145-152.

[11] Y. L. Abdel-Magid and M.M. Dawoud, Optimal AGC tuning with genetic algorithms, Electr. Power Syst. Res., 38 (1996) 231-238. 


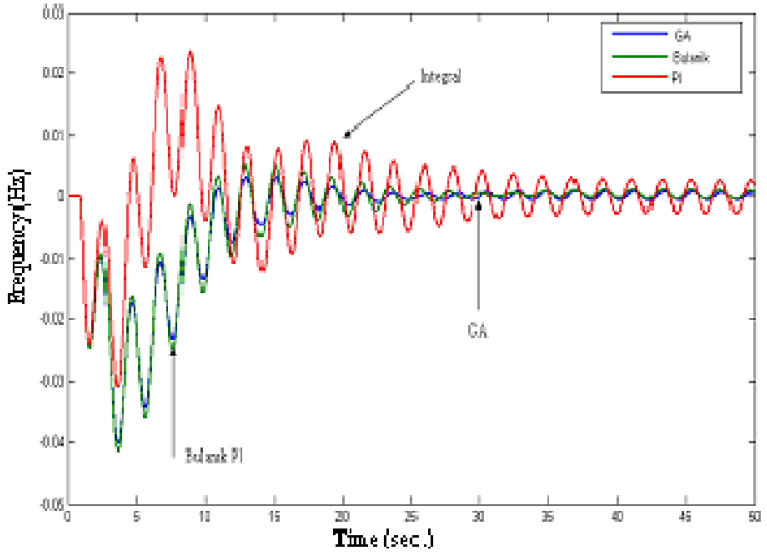

(a)

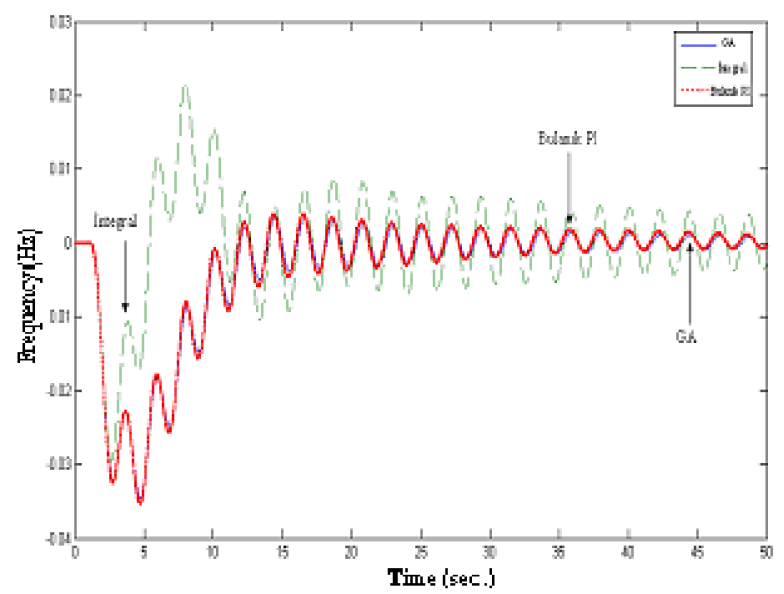

(b)

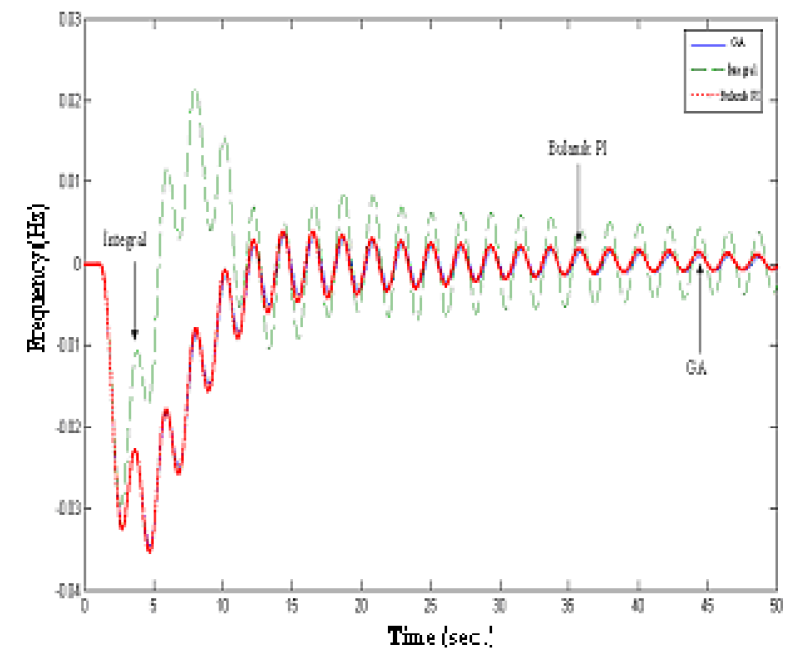

(c)

Figure 5. The results for 0.01 p.u. step load perturbations at first area of power system with three areas (a) $\Delta \mathrm{f}_{1}$ (b) $\Delta \mathrm{f}_{2}(\mathrm{c}) \Delta \mathrm{f}_{3}(\mathrm{~d}) \Delta \mathrm{P}_{12}$

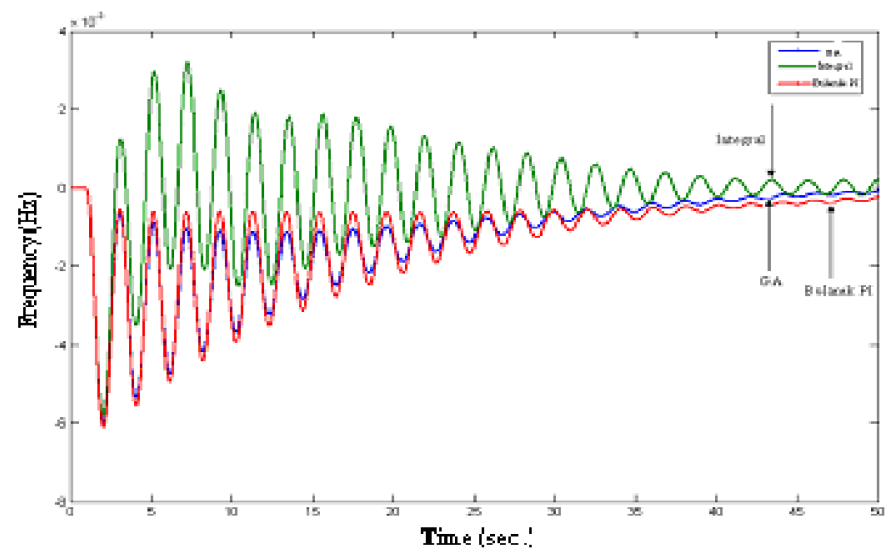

(d)



( e)



(f)

The results for 0.01 p.u. step load perturbations at first area of power system with two areas (e) $\Delta \mathrm{f}_{1}(\mathrm{f}) \Delta \mathrm{f}_{2}$ 


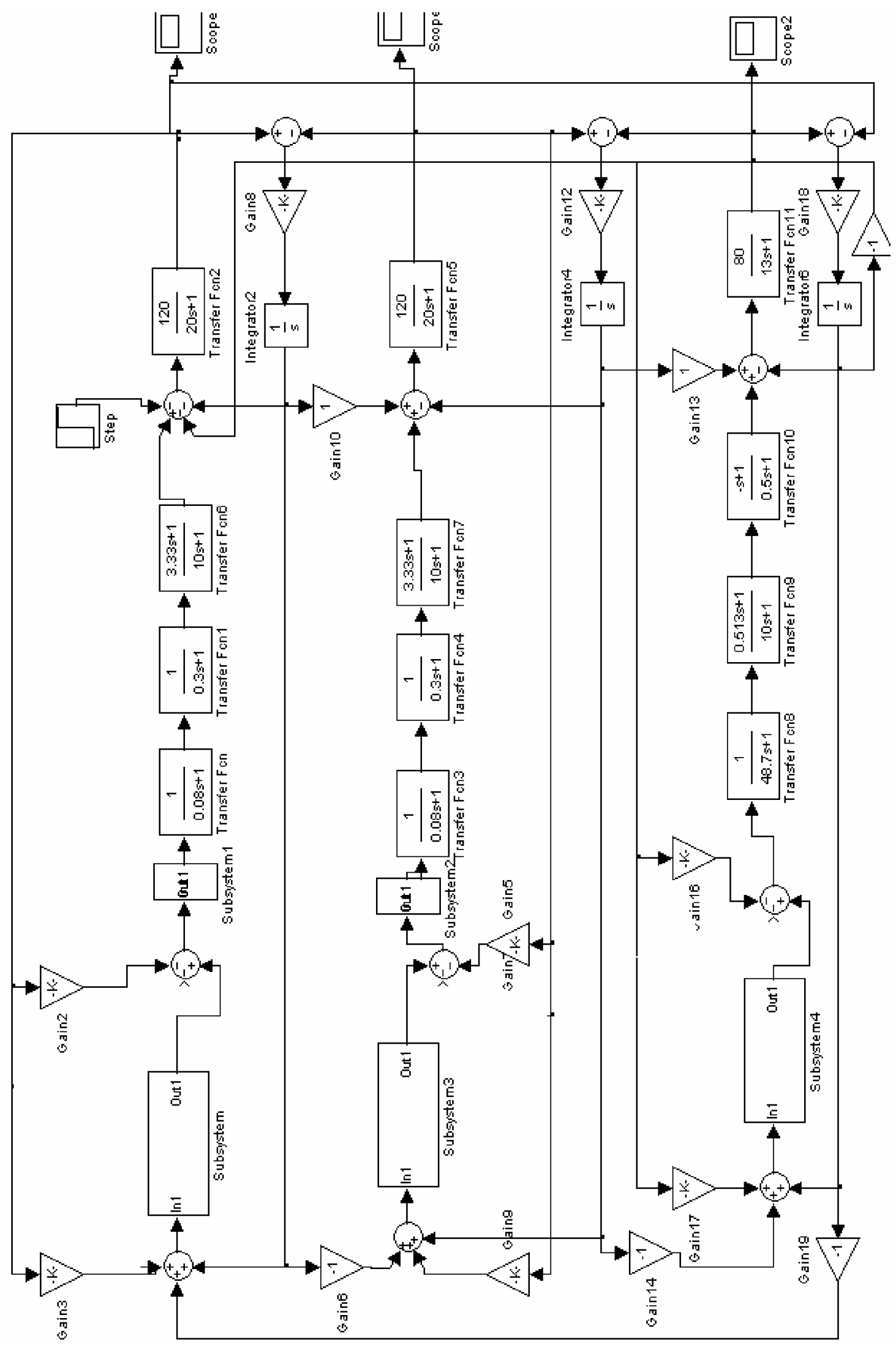

